\title{
La violencia como recurso dramático en Suplicantes de Esquilo
}

\author{
Isidro Molina Zorrilla ${ }^{1}$
}

Recibido: 28 de Noviembre de 2020 / Aceptado: 8 de Febrero de 2021

Resumen. Suplicantes de Esquilo es una tragedia cargada de violencia. Partiendo de la base de que el motivo que explica la huida que lleva al grupo de cincuenta muchachas a suplicar asilo en Argos es su miedo a sufrir violencia sexual por parte de sus cincuenta primos, Esquilo utiliza la amenaza de este tipo de violencia como un recurso dramático que motiva y desarrolla el drama. En el presente trabajo se analiza la expresión y la puesta en escena de esta violencia sugerida en los dos puntos climácicos de la pieza de Esquilo: la amenaza de suicidio durante la súplica y el posterior intento de rapto por parte de los egipcios. Palabras clave: Esquilo, Suplicantes, violencia sexual, súplica, puesta en escena.

\section{[en] Violence as dramatic resource in Aeschylus' Suppliants}

\begin{abstract}
Aeschylus' Suppliants is a very violent play. Assuming that the reason for the flight of fifty maidens who plead asylum in Argos is their fear of suffering sexual violence by their fifty cousins, Aeschylus uses the threat of this type of violence as an essential resource for dramatic purposes. This paper focuses on analysing the expression and staging of suggested violence in two climaxes in Aeschylus' Suppliants: the Danaids' threat of suicide during the supplication and the subsequent attempted abduction by the Egyptians. Keywords: Aeschylus, Suppliants, sexual violence, supplication, staging.
\end{abstract}

Sumario. 1. Introducción. 2. Origen de la violencia. 3. La amenaza de suicidio como recurso durante la súplica. 4. Intento de rapto, una violencia esperada. 5. Representación escénica de la violencia. 6. Conclusiones.

Cómo citar: Molina Zorrilla, I. (2021), La violencia como recurso dramático en Suplicantes de Esquilo, en Cuadernos de Filología Clásica. Estudios griegos e indoeuropeos 31, 21-34.

\section{Introducción}

En Suplicantes ${ }^{2}$, Esquilo lleva a escena el mito de las cincuenta muchachas, hijas de Dánao, que huyen de la unión impuesta con sus cincuenta primos, hijos de Egipto.

1 Universidad de Málaga. Departamento de Filología Griega, Estudios Árabes, Lingüística General, Documentación y Filología Latina.

molinazorrilla@uma.es

Aprovecho para agradecer a los evaluadores anónimos de la revista y a las profesoras Dra. Marta González González y Dra. Lucía Presentación Romero Mariscal sus inestimables comentarios, que han contribuido a mejorar este artículo.

2 La edición utilizada es la de West (1998) y se señalan en nota los lugares en los que me aparto de ella. Las traducciones son propias, aunque he consultado otras, especialmente la de Ramos Jurado (2017). 
La obra fue estrenada en 463 a.C. como parte de una probable tetralogía sobre las Danaides, de la que solo se conserva Suplicantes. Egipcios, Danaides y el drama de sátiros Amímone completarían esta tetralogía que desarrollaría un mito que ya habría sido tratado en el poema épico perdido Danaida, circunscrito al ciclo argivo ${ }^{3}$. Su huida las lleva a Argos, patria de Ío, de la que descienden, y recién desembarcadas, en un espacio sagrado al aire libre, dirigen su súplica de asilo al gobernante de la ciudad, Pelasgo. La obra de Esquilo dramatiza este episodio y la posterior intervención violenta de los hijos de Egipto, quienes tratan de llevárselas por la fuerza una vez que las muchachas han recibido garantías de asilo en Argos.

Suplicantes ha sido durante mucho tiempo criticada por su falta de acción dramática. Sin embargo, parto de la postura de que todas estas consideraciones están superadas: no es verdad que no haya más acción por inhabilidad dramatúrgica de Esquilo ni la falta de acción resta valor trágico a la obra ${ }^{4}$. Hay, en todo caso, acción sugerida: Esquilo no llega a representar la violencia del drama en escena, pero revela un gran control dramático al jugar con las expectativas del espectador ante una eventual acción violenta.

En el corpus de tragedias griegas conservadas, la secuencia súplica-asilo-violencia, como elementos sobre los cuales se articula la obra, se repite hasta en cinco ocasiones, a saber, Suplicantes y Euménides de Esquilo, Edipo en Colono de Sófocles y Heraclidas y Suplicantes de Eurípides ${ }^{5}$. En estas tragedias, que siguen una serie de convenciones argumentales de las que la Suplicantes esquílea se configura como arquetipo, se espera que, tras la solicitud de asilo por parte de un grupo de fugitivos a un soberano virtuoso, tenga lugar una respuesta violenta por parte de sus perseguidores. Esquilo centra su tragedia sobre las Danaides en dos episodios del mito que encajan con la secuencia mencionada: la súplica de asilo en Argos a Pelasgo y, una vez garantizada la protección argiva, el intento de rapto por parte de los egipcios. En este trabajo analizo ambos pasajes que, además de presentar analogías a nivel estructural e ideológico como puntos climácicos de la pieza, están caracterizadas por la habilidad de Esquilo para conmover al espectador mediante una violencia que queda

\footnotetext{
El orden de representación de la trilogía de tragedias de Esquilo sobre las Danaides (e, incluso, que formaran parte de la misma tetralogía, como señala Taplin 1977: 194-198, con bibliografía) es una cuestión debatida entre los estudiosos que no ha alcanzado consenso. El P. Oxy. 2256 fr. 3 sí confirma que Danaides, de la que se conservan tres fragmentos, ocuparía el último lugar en la trilogía. Respecto a las dos primeras, el orden tradicionalmente aceptado, defendido por Winnington-Ingram (1961) y seguido por alguno de los comentaristas más recientes de la obra (Sandin 2005: 9-12), sitúa Suplicantes en primer lugar y Egipcios a continuación. Sin embargo, estudiosos como Sommerstein (2013: 100-108) defienden que Suplicantes ocuparía el segundo lugar, precedida de Egipcios. Según esta tesis, la obra dramatizaría los intentos de Dánao, rey de Egipto sin heredero masculino, de evitar ser asesinado por su yerno, según habría vaticinado un oráculo. Esto explicaría la aversión al matrimonio que habría inculcado en sus hijas, el rechazo, contrario a la ley egipcia, a la propuesta de Egipto de casar a sus sobrinas con sus hijos y la consecuente declaración de guerra y necesidad de huida. Apunta Sommerstein, empero, que, debido a la ausencia de alusiones al oráculo en la pieza conservada, las Danaides no parecen conocer su existencia, por lo que su solicitud de asilo, alegando amenazas de violencia, es genuina. Si actúan o no manipuladas por su padre sin duda afecta la interpretación de la trilogía y sería necesario un posicionamiento claro en esta cuestión. Esto, sin embargo, no repercute en la expresión y puesta en escena de la violencia en Suplicantes ni, en concreto, en que sea la violencia sexual la causa principal que motiva la necesidad de protección de las Danaides en la obra, pues, en ambos escenarios, la amenaza de violencia es real.

4 Librán Moreno (2005: 273-351) responde uno a uno a los diferentes problemas dramáticos que plantea Suplicantes y que fueron utilizados por la crítica moderna para tachar la obra de trabajo primerizo. Confirmada la datación de la pieza en 463 a.C., Librán Moreno justifica que, en todo caso, Suplicantes es un ejercicio arcaizante de un dramaturgo innovador (2005: 274).

$5 \quad$ Clasificación de Taplin (1977: 192).
} 
solo sugerida. Exponer cómo se expresa y se representa en escena esa violencia que nunca llega a materializarse es el objetivo del presente estudio. Y, para ello, es preciso aclarar antes cuáles son los motivos que originan esa violencia.

\section{Origen de la violencia}

Al inicio de Suplicantes, en la párodos, tras invocar a Zeus, el coro de Danaides can-

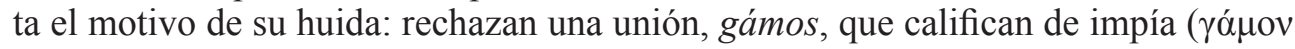

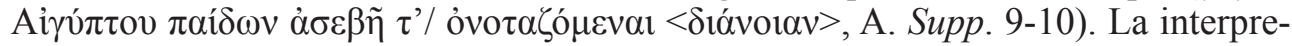
tación del $\alpha v \tau o \gamma \varepsilon v \tilde{\eta} \varphi v \xi \alpha v o p i ́ \alpha v$ del verso anterior ha generado debate entre los estudiosos sobre las implicaciones que subyacen en esta huida ${ }^{6}$. El sintagma parece voluntariamente multívoco y su ambigüedad ha sido reconocida por los comentaristas, entre ellos Sandin (2005: 42-44), Bowen (2013: 143-144) o Sommerstein (2019:

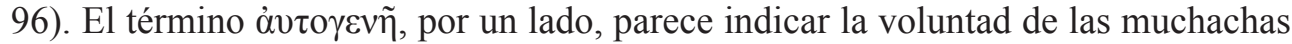

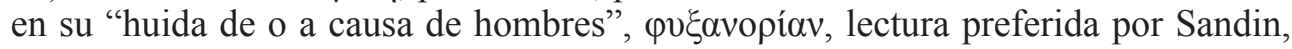
en contraste con el anterior $\delta \eta \mu \eta \lambda \alpha \sigma i \alpha v$ (A. Supp. 6), término que, señala Bowen, es igualmente ambiguo y apunta a un "destierro de o propiciado por la comunidad".

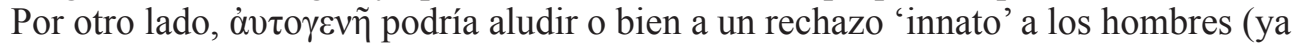
en general, ya a los egipcios en concreto, apunta Sommerstein), o bien a un rechazo a hombres 'del mismo linaje'. Aunque Esquilo sugiera una posible misandria, parece menos probable que las Danaides nieguen una unión endogámica per se, de la que

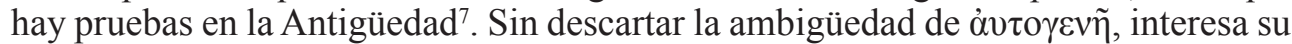
lectura como calificativo: Esquilo destaca desde el principio la consanguineidad de las Danaides con sus primos, no tanto para justificar con ello el rechazo en sí mismo, sino para resaltar la impiedad de la violencia que pretenden imponer los egipcios, que queda acrecentada por darse entre personas unidas por lazos de sangre ${ }^{8}$.

La unión que pretenden los egipcios con sus primas no es consentida. Durante la

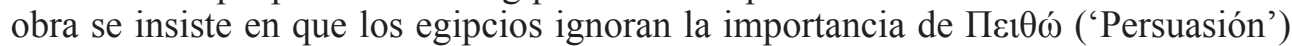
y buscan una unión mediante imposición por la fuerza, y el intento final de rapto no hace sino materializar mediante amenazas y conatos de violencia los miedos que las muchachas han expresado a lo largo de la pieza. En este contexto, entender gámos solo como una unión nupcial no terminaría de explicar la profunda aversión que origina la huida de las Danaides: el suyo es el miedo a sufrir violencia sexual por parte de sus primos. ${ }^{9}$. Así lo manifiestan al principio de la obra, en la misma párodos: desean que sus primos, a los que llaman "violento enjambre masculino del linaje

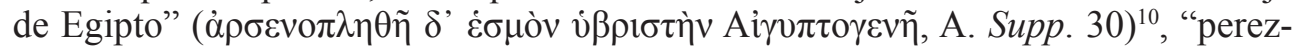
can antes de que algún día asalten a la fuerza unos lechos que la ley les prohíbe

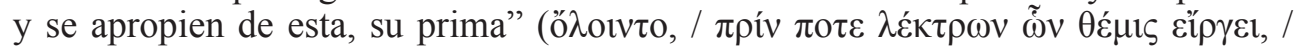

$6 \quad$ Iriarte \& González (2008: 115-117, con bibliografía) realizan un estado de la cuestión con las diferentes interpretaciones que la crítica ha dado a este verso.

7 MacKinnon (1978: 77) ya descartaba el incesto, entre otros aspectos, como condicionante de la huida. Igualmente ocurre en trabajos recientes sobre las motivaciones de la huida de las Danaides: los datos históricos avalan que la endogamia era una práctica normalizada entre primos, $c f$. Cuniberti (2001: 152), Pòrtulas Ambrós (2009: 274), Fialho Zambuio (2009: 186).

$8 \quad$ MacKinnon (1978: 79-80), Iriarte \& González (2008: 117), Papadopoulou (2011: 59-60).

9 Sobre la ambigüedad del término gámos, que puede significar unión sexual pacífica o violenta según el contexto, $c f$. González González (en prensa).

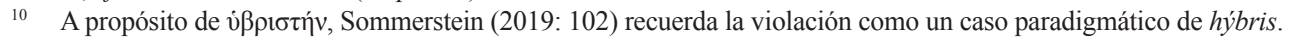




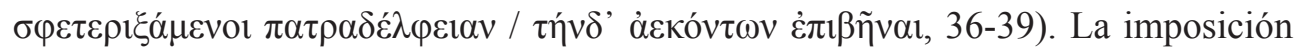
sexual de los egipcios ilegitima las posibilidades de hacer efectivo un matrimonio que, de ser consensuado (recordemos que el padre de las jóvenes, Dánao, también se opone a esta unión), estaría amparado por la legalidad. El final de la pieza, una vez Pelasgo ha ahuyentado a los egipcios, abunda en esta cuestión: las Danaides no rechazan el matrimonio como tal, sino una unión por la fuerza $\left(\mu \eta \delta\right.$ ' vं ${ }^{\prime}$ ' $\alpha$ ó $\gamma \kappa \alpha \varsigma$ /

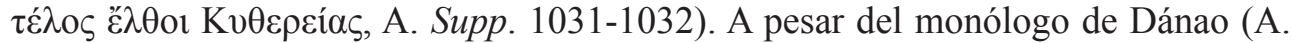
Supp. 980-1013), que apunta una posible hýbris contra Afrodita, y la petición del

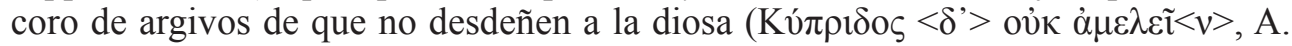
Supp. 1034), estos mismos la invocan junto a Persuasión (A. Supp. 1039-1040). Incluso en su última intervención, las propias muchachas piden que Zeus las libre

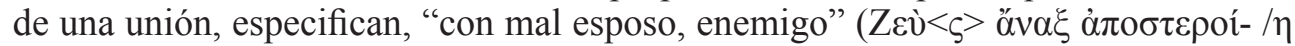

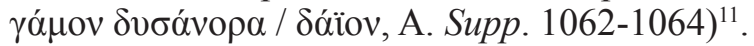

El miedo a ser violadas por sus primos como causa de su rechazo es uno de los temas de fondo de la pieza, y Esquilo incide en la ilegitimidad de ese intento mediante una imagen recurrente: la caza como metáfora de la imposición de la violencia sexual. Esta, además, queda agravada por la consanguineidad, reflejada en la imagen de caza entre dos grupos de aves: Dánao compara a sus hijas con palomas asustadas que han de buscar refugio ante el asedio de los halcones. Y, como palomas asustadas, las Danaides huyen de Egipto y a su llegada a Argos suplican asilo para escapar de los halcones ${ }^{12}$.

\section{La amenaza de suicidio como recurso durante la súplica}

Si bien, según las convenciones dramáticas, en una tragedia de súplica-asilo-violencia se podría esperar la escena violenta en el último tercio del drama, y de hecho así tiene lugar en Suplicantes, el espectador se encuentra, además, en esta ocasión, con un tipo diferente y concreto de violencia que tiene lugar durante el desarrollo de la súplica. En el punto culminante de la plegaria, expuestas sus razones, y como último recurso para favorecer su causa, las jóvenes doncellas amenazan con suicidarse si no consiguen el asilo solicitado.

Como fugitivas asediadas por sus perseguidores, las Danaides han acudido a Argos desvalidas, vulnerables: "eres una extranjera pobre y fugitiva" afirma su padre

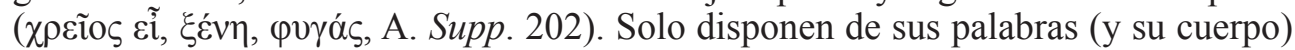
para llevar a cabo el ritual de la súplica ${ }^{13}$ y lograr el asilo que las proteja de sus primos. Durante la párados han presentado los argumentos clave que alegarán para

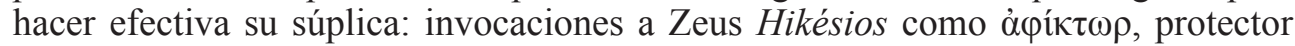

11 Papadopoulou (2011: 51-64) aborda la causa del rechazo de las Danaides a sus primos como un conflicto de género. Su aversión al matrimonio no es general, sino particular, y lo expresan en términos del miedo típico de la doncella al matrimonio como una forma de violación si este no es consentido.

12 Sobre la simbología aviar y cinegética en Esquilo, ya presente en el canto XXII de la Ilíada durante el enfrentamiento entre Aquiles y Héctor, $c f$. Iriarte \& González (2008: 82-85; 112-119, con bibliografía).

13 Aunque el acto de la súplica, hiketeía, bien cara a cara, bien en contacto con un altar u otro espacio sagrado, está tipificado como un ritual religioso con sus propias convenciones, empleo aquí el término en un sentido más amplio, atendiendo al hecho de que, durante el desarrollo de la súplica, la actitud de las Danaides se reviste de cierta ritualidad al seguir las recomendaciones de su padre para que puedan ser identificadas como suplicantes. Según Gould (1973: 89-90), en Suplicantes (y en la tragedia en general) se aprecia una revisión de la súplica desde la perspectiva ateniense del siglo V a.C., que propone una versión 'sofisticada', política, de una institución social primitiva. 
de los suplicantes, desde el primer verso de la pieza; alusiones a su origen, que las hace descender de Zeus e Ío, natural de Argos, lo que, por tanto, las emparenta con el rey Pelasgo, a quien irán dirigidas sus súplicas; y, especialmente, el motivo de su huida: la amenaza de sufrir violencia física y sexual por parte de sus perseguidores. Desde el principio hay, pues, una idea de violencia reprobable, un recurso continuo a lo largo de la pieza, que funciona a dos niveles. El primero, argumental: las Danaides deben insistir en que son potenciales víctimas de violencia física y sexual para conmover a Pelasgo y lograr el asilo. El segundo, dramático: al sugerir Esquilo una eventual ejecución de la violencia, genera suspense.

Al comienzo del primer episodio, Dánao observa la llegada de la comitiva real y asume su rol, ya anticipado en la párodos (A. Supp. 11), de padre ( $\pi \alpha \tau \eta ́ \rho)$, respon-

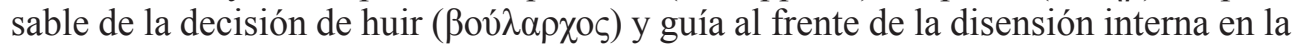
familia ( $\sigma \tau \alpha \sigma i ́ \alpha \rho \chi \varsigma)$. Desde esa posición, y de cara al inminente desarrollo del ritual de la súplica, aconseja a sus hijas refugiarse en torno al altar del santuario, sentadas

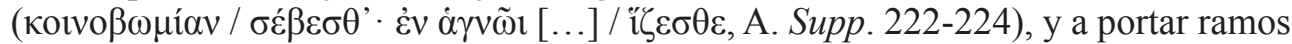
de olivo ceñidos de lana blanca con la mano izquierda que las identifiquen como

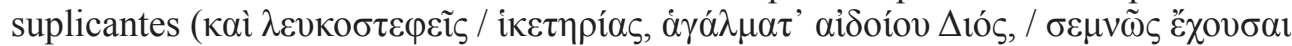

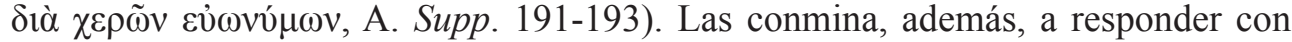

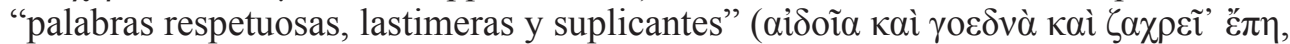

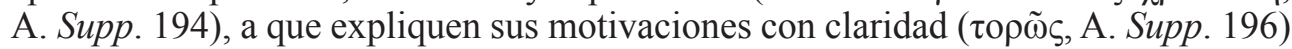
y a que eviten usar un tono osado ( $\theta \rho \alpha \sigma u ́$, A. Supp. 197), "pues a quienes están en

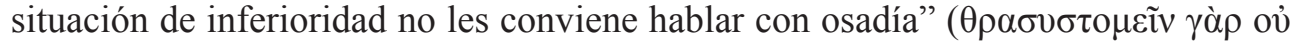

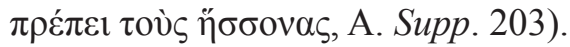

Con la llegada de Pelasgo y su séquito, que se asombra al ver a un grupo de bárbaras $\dot{\alpha} \pi \rho \xi_{\xi} \varepsilon v o 1$ (A. Supp. 239), sin próxenos, junto al altar y las estatuas de dioses que han adornado con ramos de suplicantes, comienza la súplica. Las Danaides afirman descender de la argiva Ío y detallan, pese al recelo inicial del rey, la genealogía que las relaciona con el propio Pelasgo y su pueblo (A. Supp. 275-326). El favor de Pelasgo parece más difícil de lograr cuando el corifeo de las Danaides anuncia que huye

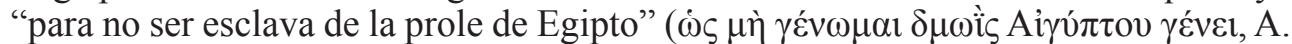
Supp. 335). El rey cuestiona la legitimidad de renegar de una unión que podría estar sujeta a la ley del país del que proceden (A. Supp. 387-389) y se estremece al pensar en la guerra que su pueblo habría de afrontar de aceptar la súplica ("graves palabras

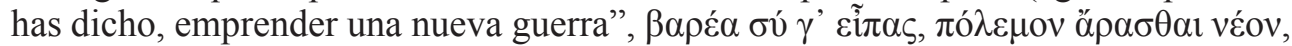
A. Supp. 342). Dada la gravedad de la situación, Pelasgo, como representante del pueblo argivo ${ }^{14}$, manifiesta la necesidad de consultar con la ciudadanía un asunto que podría acarrear consecuencias funestas para la ciudad (A. Supp. 365-369).

Ante las reticencias del rey, las Danaides, que no conciben que un rey no sea soberano (A. Supp. 370-375), continúan su súplica ignorando los consejos de mesura y humildad que les había dado su padre. Así, comienzan por anticipar el sacrilegio

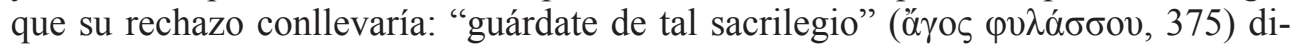
cen, evocan la impía violencia que recibirían por parte de los egipcios en el espacio sagrado al que se acogen (A. Supp. 423-432) y, tras recordar a Zeus como garante de la súplica que vigila el desarrollo del ritual (A. Supp. 381-386, 402-406), anuncian, a modo de primera amenaza velada, que las consecuencias de su decisión las pagarán

14 Anacronismo de la tragedia: la monarquía queda subordinada a la soberanía democrática, reflejo de la Atenas en la que se escriben y representan las tragedias. 


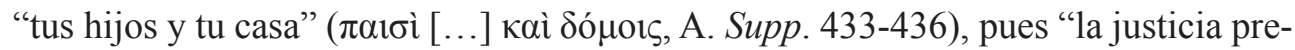

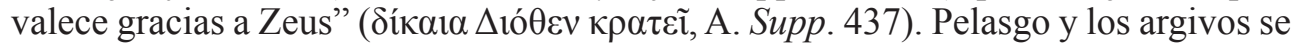
encuentran, pues, en una encrucijada: sea cual sea la decisión que tome la asamblea, la ciudad recibirá perjuicio.

En el verso 438 comienza un nuevo episodio y, tras un monólogo de Pelasgo, el corifeo enuncia "las últimas de mis muchas palabras dignas de respeto" ( $\pi \mathrm{o} \lambda \lambda \tilde{\omega} \mathrm{V}$

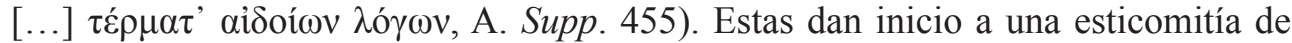
trece versos donde las Danaides, de manera enigmática ( $\alpha i v \imath \gamma \mu \alpha \tau \tilde{\omega} \delta \varepsilon \varsigma \tau$ o Supp. 464) y en claro contraste con los consejos de su padre, terminan por amenazar con desatar los cinturones que ciñen sus ropajes y colgarse con ellos de las estatuas de las divinidades erigidas en la colina sagrada donde se encuentran (A. Supp. 465) ${ }^{15}$. Estas palabras las recibe Pelasgo como un "latigazo para mi corazón" ( $\mu \alpha \sigma \tau \iota \kappa \tau \tilde{\rho} \rho \alpha$

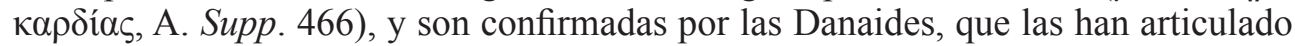
"con bastante claridad" ( $\sigma \alpha \varphi \varepsilon ́ \sigma \tau \varepsilon \rho o v$, A. Supp. 467). De cometer suicidio, al sacrilegio provocado por el rechazo de suplicantes acogidos a un santuario público, habría de sumar el miasma por la presencia de cadáveres en espacio sagrado. Y es la insi-

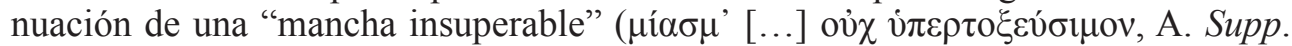
473) lo que finalmente mueve a un rey dispuesto a todo para lograr el favor de su pueblo a la hora de aceptar la súplica de las muchachas y afrontar, en consecuencia, una guerra contra los egipcios ${ }^{16}$.

La amenaza de suicidio en espacio sagrado se yergue como un importante recurso de exhortación moral que lleva a las Danaides a utilizar su propia vulnerabilidad contra Pelasgo y los argivos ${ }^{17}$. El ritual de la súplica, pues, encierra en este caso un acto de agresión del suplicante contra su huésped. Sin embargo, esa amenaza de suicidio podría verse como un recurso legítimo durante el desarrollo de la súplica debido a la situación de extrema necesidad del suplicante ${ }^{18}$. Por su enunciación enigmática ${ }^{19}$, que desoye deliberadamente los consejos de su padre, la amenaza de suicidio de las Danaides podría verse como una táctica para persuadir a Pelasgo y favorecer el asilo, o incluso podría ser entendida como una suerte de maldición, como la insinuación del castigo que los argivos recibirán de ignorar sus palabras de súplica. En cambio, dada la situación, esta amenaza de suicidio podría entenderse realmente como una declaración de intenciones ${ }^{20}$, la última salida de quienes no pueden escapar de una violencia que aborrecen y repudian. Tal es su desesperación que asumen como daño colateral el miasma que implicaría llevar a cabo su amenaza.

La amenaza de suicidio añade nuevas capas de complejidad a la violencia ya sugerida en la pieza. Hasta este punto del drama, las Danaides eran objeto de violencia por parte de sus perseguidores, pero, al amenazar a los argivos con el suicidio si son rechazadas, se convierten también en sujeto posible de violencia. Asimismo, si es aceptada, la propia súplica podría traer represalias contra los argivos, pues los

15 Sobre el suicidio de las mujeres en la tragedia mediante el ahorcamiento, $c f$. Loraux (1989: 31-54).

16 Así lo recoge Parker (1983: 315) en su monografía sobre el miasma en la religión griega: "Pelasgus in Aeschylus is constantly warned of the danger involved in refusing the Danaids' supplication, and this is the consideration that finally sways him and his people".

17 Gould (1973: 100), Brill (2009: 165).

18 Según Gould (1973: 81-82), la hiketeía (súplica) es “a game of life and death” sujeto a reglas ambiguas que pueden ser interpretadas de la manera más conveniente según las circunstancias.

19 Sobre el habla enigmática que parte de la tradición atribuye a las mujeres, incluidas las Danaides en este pasaje, $c f$. Iriarte Goñi (1990: 58-59; 126-127).

20 Bednarowski (2010: 198). 
egipcios la entenderán como una declaración de guerra. En cualquier caso, los argivos serán objeto de violencia. Esto no es ajeno al mito: es conocida la condición de estas muchachas como objeto de una violencia injustificada y es esta la razón por la que han huido de Egipto. Lo que interesa aquí del tratamiento de Esquilo es cómo, ante una situación sin salida, las propias Danaides podrían convertirse en sujeto de violencia hacia ellas mismas y hacia sus anfitriones ${ }^{21}$.

Desde una perspectiva dramática, la amenaza de suicidio funciona también como un portentoso golpe de efecto. Esquilo, al situarla al final de la súplica, en el verso undécimo de una esticomitía enigmática, tras un largo pasaje lírico, demuestra que sabe el impacto dramático que puede causar en el público la imagen sugerida de cincuenta cadáveres de jóvenes doncellas en un espacio sagrado. Con esta insinuación supera las expectativas de violencia del espectador (que espera más adelante la intervención violenta de los egipcios) y genera más suspense, una necesidad mayor de urgencia que acrecienta el desasosiego que producirá el siguiente estásimo en el que las jóvenes esperan, llenas de dudas, la resolución de la asamblea. Al llevar al límite el suspense, la feliz noticia de una resolución positiva de la demanda de asilo es doblemente celebrada: por las Danaides y por el público.

\section{Intento de rapto, una violencia esperada}

La amenaza de suicidio de las Danaides supone un golpe de efecto para el espectador, pues sugiere con ella Esquilo un tipo de violencia inesperada; en cambio, por las propias convenciones dramáticas, en una obra de súplica-asilo-violencia como $\mathrm{Su}$ plicantes se espera que en el último tercio se dé algún tipo de intervención violenta por parte de los perseguidores.

Las Danaides solicitan asilo por el miedo a ser capturadas y finalmente violadas por sus primos, algo que claman desde la misma párodos, hasta el punto de desear su muerte en alta mar (A. Supp. 30-39). Además, la posibilidad de una inminente intervención acecha cada episodio: en un estásimo durante el desarrollo de la súplica, en los versos 423-432, imploran a Pelasgo que no permita que sean arrastradas de los altares a los que se acogen. Sus temores se confirman cuando, una vez han sido informadas de que la asamblea argiva ha votado su protección, Dánao interrumpe el estásimo celebrativo del coro en el verso 710 para anunciar el desembarco de los egipcios. Los 114 versos siguientes no hacen sino incidir en la alarmante situación que está por darse. Dánao, que al ver llegar la comitiva real aconsejó a sus hijas cómo actuar para ejecutar el ritual de la súplica, ahora les insufla ánimos y les indica que se protejan en el altar (A. Supp. 724-733, 772-773) antes de salir en busca de la ayuda argiva. Las Danaides, por su parte, expresan sus temores e inseguridades: ponen en duda la conveniencia de su huida (A. Supp. 736-738), manifiestan que prefieren morir a ser capturadas (A. Supp. 788-790, 804-805), aluden al carácter impío de la violencia que les espera (A. Supp. 751-752, 758-759) e invocan a Zeus como testigo para castigarla (A. Supp. 811-813).

21 La amenaza de suicido como último recurso durante el desarrollo de la súplica también ha sido estudiada en el contexto de la trilogía. La predisposición de las Danaides a convertirse en sujeto de violencia en este pasaje prepara al espectador para su futuro retrato como asesinas de sus maridos, $c f$. Winnington-Ingram (1961: 141-142). 
Este anuncio de la llegada de los egipcios, peculiar por su extensión, alerta al espectador sobre el cariz violento del encuentro que está por ocurrir. Este comienza en el verso 825 , cuando entra el heraldo egipcio con su séquito ${ }^{22}$. Desde aquí hasta la intervención de Pelasgo en el verso 911 se sucederán una serie de amenazas por parte del heraldo y de gritos de desamparo por parte del coro. Destaca la brutalidad de las palabras del egipcio, que defiende la supremacía de la violencia ( $\beta i ́ \alpha \beta i \tilde{\alpha} \alpha \boldsymbol{1} \pi \mathrm{o} \lambda \lambda \tilde{\alpha}$, A. Supp. 863) $)^{23}$. Ya en sus primeras intervenciones anuncia que, si las jóvenes no siguen sus órdenes, están dispuestos a arrancarles los pelos a tirones y marcarlas a fuego como esclavas ( $\tau \wedge \mu$ oì

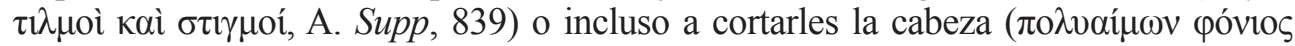

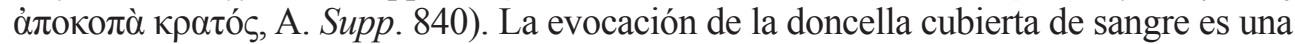
imagen de gran impacto visual que se repetirá más adelante: "ensangrentada te arrojaré

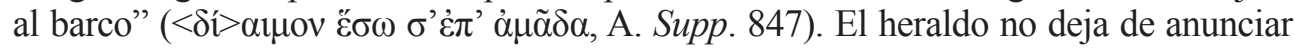
diferentes medios coercitivos para hacerlas subir a su navío (por ejemplo, "a bofetadas", $\pi \alpha \lambda a ́ \mu \alpha ı$, A. Supp. 865), mientras reconoce no temer a las divinidades de Argos (oủंor

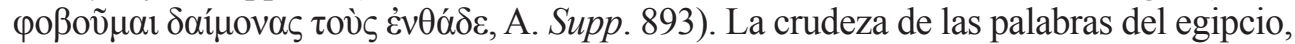
que presentan rasgos claramente barbarizados, contrasta con la expresividad de los gritos de las Danaides. Las muchachas lamentan su suerte y dudan de la protección que les brinda acogerse a sagrado: "ay, ay, padre, la ayuda de esta imagen es inútil” (oioĩ, $\pi \alpha ́ \tau \varepsilon \rho$,

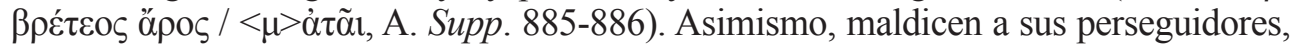
a quienes preferirían ver muertos en alta mar (A. Supp. 843-846, 867-871) y a los que comparan con animales a punto de darles caza ("araña", ’’ $\alpha \alpha \chi v o \varsigma$, A. Supp. 887, o "ser-

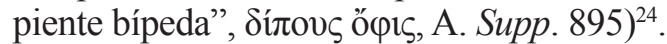

La tensión violenta in crescendo del pasaje lírico se ve interrumpida por la aparición de Pelasgo, que da inicio a un nuevo episodio. El rey, como protector de las

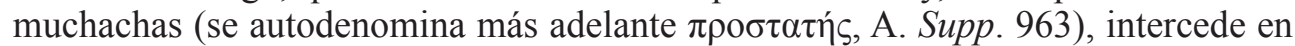
su defensa. Su entrada tiene lugar en el verso 911, en el momento en el que las amenazas están, parece, a punto de convertirse en hechos: "no habrá piedad en desgarrar

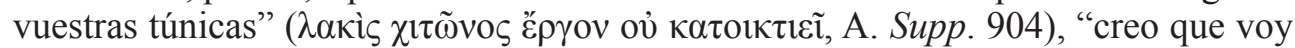

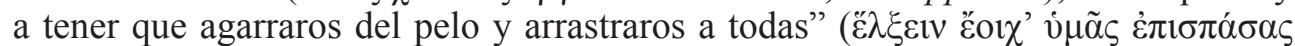
кó $\mu \eta$, A. Supp. 909). Y mientras los versos del heraldo indican una acción inminente, las hijas de Dánao confirman, en tiempo presente, que son violentadas, y dirigen un grito de socorro al soberano: "joh, caudillos, jefes de esta ciudad, sufro violen-

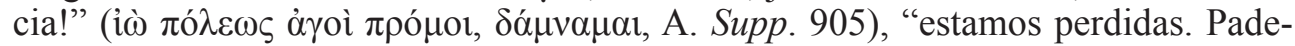

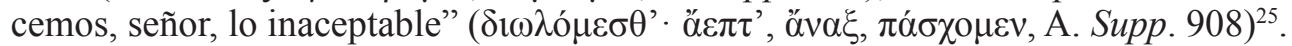

Para el espectador ateniense, la violencia evocada en este estásimo, más allá de la crudeza de las imágenes sugeridas, es una violencia reprobable e ilegítima por diferentes razones. En primer lugar, por su obvio carácter impío, pues se ejerce contra suplicantes de asilo refugiadas en un espacio sagrado, entre altares e imágenes divinas, a las que se han acogido al entonar su súplica. El suplicante, una vez asilado en un templo o espacio sagrado, pasa a formar parte de la divinidad, y atentar contra él significa aten-

22 Difiero, en este caso, con la interpretación de West (1998) por la que entraría en escena un coro de egipcios, $c f$. epígrafe siguiente.

23 West (1990: 159).

24 Se trata de un recurso recurrente a lo largo de la obra y especialmente en el estásimo anterior: la visualización del perseguidor como una bestia o monstruo salvaje a punto de darles caza.

25 La intervención de Pelasgo se inserta en el inicio de una esticomitía tras ocho versos de difícil edición. West (1998: 176) conserva la numeración original de estos versos, aunque alterna el orden, una decisión que me parece plausible por el sentido climácico del pasaje. 
tar contra Zeus Hikésios mismo ${ }^{26}$. El propio heraldo de los egipcios reconocerá más adelante no respetar más divinidades que las del Nilo (A. Supp. 922). Existe, por tanto, una distancia cultural entre el asaltante y el asilado, que se acoge a los dioses locales, pero también entre el asaltante y el espectador. Si bien las Danaides son y están caracterizadas como bárbaras, al igual que sus perseguidores, han defendido su ascendencia argiva y llevan a cabo su súplica siguiendo la costumbre griega de depositar ramos de olivo junto a los dioses de la ciudad, como el propio Pelasgo advierte en su primer encuentro (A. Supp. 241-243). Es decir, se añade a la violencia contra el suplicante el componente bárbaro, la otredad: la violencia de los egipcios es entendida por el espectador como una amenaza a los valores democráticos atenienses representados en Argos, que ha decidido asilar a las jóvenes mediante decreto ciudadano ${ }^{27}$.

Y, por supuesto, el conato de rapto es reprobable per se y por las causas que lo motivan, como exponía más arriba. No solo pretenden imponer una unión sin persuasión, sino que durante el intento de rapto pretenden el sometimiento de sus primas previa imposición sexual. Tras el largo pasaje lírico de amenazas de violencia, lo que plantea Esquilo entre los versos 905-913, con el heraldo egipcio gritando que las arrastrarán del pelo y desgarrarán sus ropas, es la escena de una violación, la violencia sexual cuyo rechazo provocó la huida de las muchachas y que están a punto de sufrir. Cabe considerar además que la ilegitimidad de los egipcios es más grave al ser las jóvenes suplicantes aún vírgenes. El estatuto del suplicante y la condición de la virgen guardan una serie de analogías: en ambos estados, el sujeto se encuentra en los márgenes de la sociedad. El suplicante mediante el ritual de la súplica, si finalmente esta es favorecida, es aceptado dentro de una comunidad como asilado, y la joven virgen comienza a cumplir la función que se le ha asignado dentro de la sociedad una vez completa otro ritual, el matrimonio, como paso previo a la procreación. Ambas situaciones, además, están relacionadas con lo sagrado: el suplicante pasa a formar parte de la divinidad, mientras que la virginidad perpetua es de hecho una característica de ciertas divinidades y de sacerdotisas en muchos cultos. Virgen y suplicante se constituyen, pues, como intocables, lejos de toda mácula ${ }^{28}$. Por ello, el intento de rapto por parte de los egipcios en espacio sagrado implica doble sacrilegio y doble agresión: contra el suplicante asilado en un santuario, y contra la joven virgen que sufre violencia sexual.

La violencia del pasaje es vista como reprobable por su propia naturaleza, pero también por la crudeza de los términos en los que se manifiesta. El vívido lenguaje empleado contrasta, empero, con la presumiblemente escasa acción en escena. El espectador, por su conocimiento del mito y de las convenciones dramáticas, podría esperar un pasaje violento como este, pero Esquilo se apoya en la puesta en escena y el movimiento de los personajes para acrecentar el suspense y hacer del conato de violencia física un punto climácico en la pieza. Trataré de reconstruir y esclarecer estos recursos escénicos en el siguiente epígrafe.

\section{Representación escénica de la violencia}

Discernir el grado de naturalismo en la representación a partir de las indicaciones deícticas y referencias del propio texto, supone una ardua tarea que puede abordarse

\footnotetext{
Sinn (1993: 73).

Hall (1989: 190-200).

Zeitlin (1996: 127-136).
} 
desde diferentes perspectivas ${ }^{29}$. Para analizar el potencial dramático del intento de rapto, es necesario reconstruir qué lugar ocupaba cada personaje en la orquestra y sus movimientos sobre la misma. Sin embargo, la puesta en escena de Suplicantes plantea una serie de problemas sobre los que aún no se ha alcanzado acuerdo entre estudiosos y editores de la obra ${ }^{30}$. Aunque es fácilmente descartable la tradicional concepción de Suplicantes como un espectáculo multitudinario con cientos de personas en escena ${ }^{31}$, sobre otros asuntos, en cambio, no se ha alcanzado consenso. Así ocurre con la atribución del perseguidor de las Danaides, que entra en escena en el verso 825, a un coro de egipcios o al heraldo. Editores de las últimas décadas como West (1998), Vílchez Díaz (1999) o Sommerstein (2019), optan por el coro de egipcios. Sin embargo, encuentro más plausible el ejercicio minimalista defendido por Librán Moreno, según la cual el papel que se le presupone al coro de egipcios lo haría el actor que interpreta al heraldo, ya que la introducción de un nuevo coro supondría un gasto considerable para el corego. Además, la idea de la puesta en escena del intento de rapto con un coro de egipcios que ejerza violencia parece responder a argumentos hipernaturalistas que contrastan con la cualidad estilizada de la representación de la tragedia ateniense ${ }^{32}$.

También es necesario aclarar cómo estaba organizado el espacio escénico en $\mathrm{Su}$ plicantes. Cabe apuntar que la orquestra evoca un campo abierto a las afueras de Argos y no lejos del mar, en el que se eleva una suave colina, págos, sobre la que se erigen estatuas de divinidades y un altar común. La presencia de las estatuas y el altar como elementos escénicos parece probable: además de recordar al espectador el carácter sagrado del lugar, el coro interactúa con ellos durante el ritual de la súplica y los adorna con ramos de suplicantes, como advierte Pelasgo a su llegada al santuario (A. Supp. 241-242) y señalan las muchachas más adelante (A. Supp. 345). Igualmente, no hay nada que lleve a pensar que la colina no fuera físicamente perceptible por el espectador, pues su función dramática a lo largo de la obra es indispensable. Sí ha sido debatida la naturaleza de esa elevación: hay quienes defienden la existencia de la skené en el teatro ateniense del siglo $\mathrm{V}$, donde el logeíon haría las veces de colina, y hay quienes entienden la puesta en escena de Suplicantes sin skené y abogan por la instalación en la orquestra ex profeso de una plataforma elevada para este menester $^{33}$. En cualquier caso, su importancia dramática queda reflejada en palabras de Dánao: "pues desde esta atalaya que acoge al suplicante veo una embarcación"

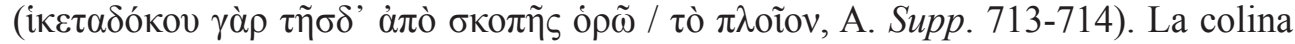
funciona como atalaya desde la que divisar y anunciar la entrada de personajes, pero a la vez divide el espacio teatral en dos, uno profano y terrenal, cercano al espectador

29 Para el desarrollo de mi investigación he considerado muy útiles las teorías de la representación estilizada basada en los gestos convencionales como apoyo al texto, de acuerdo con estudiosos como Taplin (1977) o, más claramente, Kaimio (1988).

30 Además del problema de edición que se comenta a continuación, habría que sumar el que plantea el estásimo final de la obra, donde para identificar quién da la réplica al coro de Danaides se han barajado hasta cuatro posibilidades: un coro de sirvientas, un coro de argivos, la división en dos semicoros de las Danaides o el propio Dánao. Véase Librán Moreno (2005: 338-351, con bibliografía).

31 Murray (2013: 56).

32 Librán Moreno (2005: 324-337). Sobre la convención dramática de no representar de manera visual la violencia en la tragedia ateniense, $c f$. Sommerstein (2010: 30-46).

33 Librán Moreno (2005: 360-361) en el primer caso o Di Benedetto \& Medda (2002: 83-84) en el segundo. Taplin (1977: 448-449) se hace eco de una teoría de Hammond (1972) que propone que el coro podría aprovechar una suerte de roca o elevación natural de la orografía de la colina donde se encuentra el teatro de Dioniso. 
(la orquestra), y otro alejado, centrado y elevado que refuerza la autoridad moral y religiosa de cuanto sobre él sucede (el págos $)^{34}$. Es desde este espacio desde donde las Danaides dirigen su súplica hacia Pelasgo, entre imágenes de divinidades y junto al altar común, en torno al que se han refugiado siguiendo las indicaciones de su padre para contar así con el favor divino. La construcción visual de la escena, con ellas en una posición elevada y centrada y con Pelasgo y su séquito a ras de la orquestra, concede autoridad a las hijas de Dánao y legitima, en principio, su causa, tanto como suplicantes que invocan a Zeus Hikésios, como en su calidad de descendientes que utilizan su parentesco con la divinidad para favorecer el asilo. Pero es también desde esta elevación desde donde enuncian su amenaza de suicidio, reflejo de la ironía inherente al propio ritual de la súplica. Su posición elevada y centrada destaca el poder que adquieren como suplicantes, pues ponen en jaque las opciones de un suplicado que, según él mismo reconoce, se estremece al ver las sombras de los ramos de olivo sobre los altares (A. Supp. 346), pero además incide en la gravedad de cometer tal acto en un espacio sagrado. La imagen que sugiere un miasma provocado por el suicidio de cincuenta muchachas en un espacio sagrado como este es más poderosa si cuenta con códigos visuales que lo refrenden.

A esta colina volverán las suplicantes para refugiarse ante la irrupción de los egipcios en escena. Antes, mientras aguardan solas la resolución de la asamblea, han abandonado el altar por petición de Pelasgo, quien trata así de evitar el miasma en caso de que las jóvenes cumplieran su amenaza de suicidio ${ }^{35}$. La imagen de indefensión e incertidumbre que evocan las Danaides es mayor lejos del altar, que promete protección divina. Cuando, una vez garantizado el asilo, Dánao anuncia el desembarco de los egipcios y su salida de escena para ir en busca de ayuda, el coro de muchachas vuelve a quedarse a solas en la orquestra. La desesperación que cantan las doncellas en el estásimo previo a la intervención del heraldo tiene un apoyo visual en la nueva subida al págos, esta vez y en contraste con la primera (en la que veneraban y adornaban con ramos las estatuas, una a una), apresurada, caótica, entre gritos, huyendo de unos egipcios recién desembarcados y armados con espadas, en busca de la protección que concede el altar: "vete en tu huida en busca de refugio" ( $\beta \alpha i v \varepsilon \varepsilon$

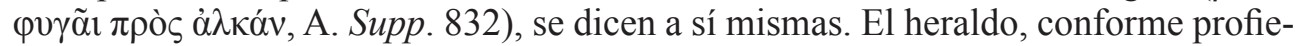
re sus crudas palabras, se acerca desde la eísodos progresivamente a la posición de las Danaides sobre el págos, acrecentando la sensación de amenaza que acompaña al texto: si quienes se encuentran sobre el págos están protegidos por la divinidad, violentar esa situación ocupando el mismo espacio es, desde la configuración visual del drama, aún más reprobable.

Este progresivo juego de huida y persecución era interpretado por actores y coro probablemente mediante movimientos estilizados y gestos convencionales que pudieran ser fácilmente divisados por los espectadores más alejados de la orquestra. Esto se ve favorecido por tratarse de un pasaje lírico, más susceptible de estilización que las partes dialogadas ${ }^{36}$. El clímax de este pasaje se alcanza en la última estrofa y antistrofa de un estásimo en el que cada intervención cantada por el coro era respon-

34 Di Benedetto \& Medda (1997: 71-72).

35 El desalojo de las Danaides fuera del altar es necesario por cuestiones técnicas, el coro debe ocupar la orquestra en los siguientes estásimos para que puedan ser también interpretados mediante danza (Sommerstein 2013: 98). Librán Moreno (2005: 310-314) comenta que, además de responder a necesidades mecánicas, este movimiento está plenamente justificado desde el punto de vista dramático.

36 De acuerdo con Taplin (1977: 35), los episodios dialogados tienden a ser representados de manera naturalista. 
dida por el heraldo de manera recitada, justo antes del inicio de un nuevo episodio en el que finalmente interviene Pelasgo en defensa de las muchachas. El heraldo, en este punto, se ha acercado lo suficiente al coro como para llevar a cabo las amenazas que ha venido profiriendo, amenazas que ahora dejan de evocar una cruenta violencia condicional y apuntan a una acción inminente mucho más plausible: rasgar las túnicas de las muchachas y tirar de sus cabellos para arrastrarlas al barco mientras las Danaides gritan, de hecho, que son violentadas (A. Supp. 903-910). Resulta, empero, dificultoso elucidar si realmente tiene lugar un contacto físico violento antes

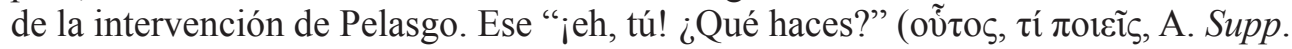
911) podría aludir, si no a un contacto físico, a un claro conato del mismo ${ }^{37}$. Independientemente de si había o no contacto, este cruce de versos, con una interpretación por parte del heraldo, presumiblemente, menos estilizada, crea una expectativa de ruptura con las convenciones de la tragedia, pues siembra en el espectador el temor de que, aunque por un breve instante, pueda llegar a ser representada violencia física en escena.

En definitiva, el efecto teatral creado en este pasaje es de gran potencia dramática. Esquilo lleva la insinuación de la violencia hasta el límite apoyándose en el trabajo de actores y coro y en la configuración visual del drama sin necesidad de llevar a escena una violencia naturalista. Esquilo haría experimentar al espectador ateniense una sensación de desasosiego acuciada ya no solo por la evocación de una violencia ilegítima en su contexto y cruel en el texto, sino también por jugar con las convenciones del drama y con las expectativas de su público.

\section{Conclusiones}

Suplicantes es una obra cargada de violencia, aunque esta no llegue nunca a representarse en escena. Y, como se ha expuesto, es importante atender a los matices de esta violencia y a las causas que motivan el rechazo a unirse con sus primos por parte de las Danaides para entender hasta qué punto el espectador ateniense podía considerarla reprobable. El temor que sienten las muchachas se explica por la violencia que los egipcios están dispuestos a ejercer sobre ellas, que es, además de verbal y física, sexual.

La amenaza de violencia sexual se configura como una suerte de leitmotiv que motiva y desarrolla el drama, una imagen que se instala en la mente del espectador y que condiciona el suspense de la pieza. Consciente de esto, Esquilo consigue, sin acción aparente, conmover al espectador, especialmente mediante dos golpes de efecto con la violencia sexual como tema de fondo. Se tratan de dos puntos climácicos de la pieza que llevan al límite el desasosiego del público por la gravedad del problema planteado y por la efectividad de los recursos dramáticos empleados por Esquilo, que sugiere acciones violentas tras largos pasajes líricos que abundan en la ilegitimidad de la violencia dentro de una puesta en escena que favorece a las suplicantes.

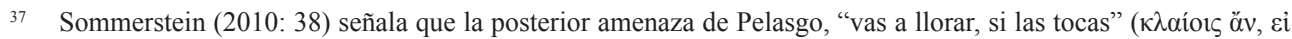

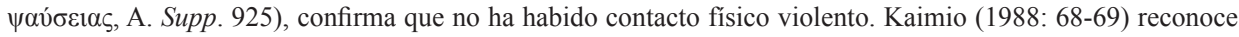
además que, si este contacto llegaba a ser representado, tal y como está configurado en escena, la diferencia sería apenas perceptible desde la posición del espectador, que sentiría igualmente temor ante la posibilidad de que las muchachas fueran agredidas. 
En primer lugar, es por miedo a la violencia sexual por lo que las Danaides huyen y solicitan asilo, y es este temor lo que las lleva a considerar el suicidio como vía de escape, incluso acogidas a un santuario, con las graves implicaciones religiosas que conllevaría. El problema que plantea Esquilo con la súplica de las Danaides, que, independientemente de su resolución, supone un perjuicio para la ciudad de Argos, no era en absoluto ajeno al público. Tanto la magnitud de la violencia de la que escapan, como la estructura dramática del episodio (que reserva la amenaza de suicidio al final de una breve esticomitía enigmática tras un largo pasaje lírico) y la configuración visual del drama (con unas suplicantes elevadas, en un espacio sagrado adornado con ramos de olivo que refrendan su súplica), generan suspense, independientemente de que el conocimiento del mito anticipara una resolución positiva. Además, la amenaza de suicidio reta las expectativas del espectador, que es testigo de cómo la Danaides pueden llegar a convertirse, a la vez, en sujeto y objeto de violencia.

En segundo lugar, y en la misma línea, aunque el espectador esperase la posterior irrupción de los egipcios, y aunque el intento de rapto quedase en mero conato y no pasase nunca a violencia representada, la puesta en escena de Esquilo en este pasaje causaría conmoción en su público. Pues no solo el intento de rapto está precedido de una extensa violencia verbal expresada en términos de violencia sexual en un momento de gran indefensión para las muchachas, sino que con él Esquilo sugiere, además, la posibilidad contraria a las convenciones dramáticas de que finalmente pueda materializarse la temida violencia que ha motivado el drama. En definitiva, la violencia sugerida se configura como el recurso principal de una obra en la que la falta de acción es solo aparente.

\section{Bibliografía}

Bednarowski, K. Paul (2010), «The Danaids’ Threat. Obscurity, Suspense and the Shedding of Tradition in Aeschylus' Suppliants», CJ 105.3: 193-212. DOI: https://doi.org/10.5184/ classicalj.105.3.193

Bowen, Anthony J. (2013), Aeschylus: Suppliant Women, Oxford, Oxbow Books.

Brill, Sara (2009), «Violence and Vulnerability in Aeschylus's Suppliants», en W. Wians (ed.), Logos and Muthos: Philosophical Essays in Greek Literature, Nueva York, State University of New York Press: 161-180.

Cuniberti, Gianluca (2001), «Le Supplici di Eschilo, la fuga dal maschio e l'inviolabilità della persona», MH 58.3: 140-156. DOI: http://doi.org/10.5169/seals-45175

Di Benedetto, Vincenzo \& Medda, Enrico (2002), La tragedia sulla scena. La tragedia greca in quanto spettacolo teatrale, Turín, Einaudi.

Fialho Zambuio, Maria do Céu (2009), «Eros y violencia en Las Suplicantes de Esquilo», en F. De Martino \& C. Morenilla (eds.), Legitimación e institucionalización política de la violencia, Bari, Levante Editori: 185-193.

González González, Marta (en prensa), «Las guerras de Esquilo y el léxico de la violencia contra las mujeres», en Homenaje a la Dra. Fátima Silva, Coimbra, Universidade de Coímbra.

Gould, John (1973), «Hiketeia», JHS 93: 74-103. DOI: https://doi.org/10.2307/631455

Hall, Edith (1989), Inventing the Barbarian: Greek Self-definition through Tragedy, Oxford, Clarendon Press.

Hammond, Nicholas Geoffrey L. (1972), «The Conditions of Dramatic Production to the Death of Aeschylus», GRBS 13: 387-450. 
Iriarte Goñi, Ana (1990), Las redes del enigma: voces femeninas en el pensamiento griego, Madrid, Taurus.

Iriarte, Ana \& González, Marta (2008), Entre Ares y Afrodita: Violencia del erotismo y erótica de la violencia en la Grecia Antigua, Madrid, Abada.

Kaimio, Maarit (1988), Physical Contact in Greek Tragedy. A Study of Stage Conventions, Helsinki, Suomalainen Tiedeakatemia.

Librán Moreno, Míriam (2005), Lonjas del banquete de Homero. Convenciones dramáticas en la tragedia temprana de Esquilo, Huelva, Servicio de Publicaciones de la Universidad de Huelva.

Loraux, Nicole (1989), Maneras trágicas de matar a una mujer, trad. cast., Madrid, Visor (obra original publicada en 1985).

MacKinnon, John Kenneth (1978), «The Reason for the Danaid's Flight», CQ 28.1: 74-82. DOI: https://doi.org/10.1017/S0009838800037745

Murray, Gilbert (2013), Esquilo, trad. cast., Madrid, Gredos (obra original publicada en 1940).

Papadopoulou, Thalia (2011), Aeschylus: Suppliants. Companions to Greek and Roman Tragedy, Londres, Bristol Classical Press.

Parker, Robert (1983), Miasma. Pollution and Purification in Early Greek Religion, Oxford, Clarendon Press.

Pòrtulas Ambrós, Jaume (2009), «Le ragioni delle Danaidi», en F. De Martino \& C. Morenilla (eds.), Legitimación e institucionalización política de la violencia, Bari, Levante Editori: 271-304.

Ramos Jurado, Enrique Ángel (2017), Esquilo: Tragedias, Madrid, Alianza.

Sandin, Pär (2005), Aeschylus 'Supplices: Introduction and Commentary on vv. 1-523, Lund, Symmachus.

Sinn, Ulrich. (1993), «Greek sanctuaries as places of refuge», en N. Marinatos, \& R. Hägg (eds.), Greek Sanctuaries, Londres - Nueva York, Routledge: 70-87.

Sommerstein, Alan H. (2010), The Tangled Ways of Zeus and other studies in and around Greek Tragedy, Oxford, Oxford University Press.

Sommerstein, Alan H. (2013), Aeschylean Tragedy, Londres - Nueva York, Bloomsbury.

Sommerstein, Alan H. (2019), Aeschylus Suppliants, Cambridge, Cambridge University Press.

Taplin, Oliver (1977), The Stagecraft of Aeschylus. The Dramatic Use of Exits and Entrances in Greek Tragedy, Oxford, Clarendon Press.

Vílchez Díaz, Mercedes (1999), Esquilo: Tragedias II, Madrid, Consejo Superior de Investigaciones Científicas (Alma Mater).

West, Martin L. (1990), Studies in Aeschylus, Stuttgart, Teubner.

West, Martin L. (1998), Aeschyli Tragoediae cum incerti poetae Prometheo, Stuttgart, Teubner.

Winnington-Ingram, Reginald P. (1961), «The Danaid Trilogy of Aeschylus», JHS 61: 141152. DOI: https://doi.org/10.2307/628084

Zeitlin, Froma I. (1996), Playing the Other. Gender and Society in Classical Greek Literature, Chicago, University of Chicago Press. 